Rev.MVZ Córdoba 17(3):3103-3104, 2012.

\title{
EDITORIAL
}

\section{Los evaluadores y su compromiso con la academia}

\author{
The referees and their commitment to the academy
}

Como es conocido por todos los involucrados en la publicación de artículos científicos o manuscritos, hoy también llamados "compuscritos", el proceso de revisión de los mismos es fundamental para evaluar la calidad científica antes de su posible publicación. Este procedimiento se conoce como "arbitraje" o "juicio de pares o evaluadores" ya que en el proceso intervienen dos o más investigadores o científicos expertos en una temática específica, a quienes justamente se les denomina árbitros (referees), pares, revisores o evaluadores, con gran responsabilidad en el juzgamiento de la calidad de los manuscritos que se van a publicar en caso de que ellos sean aprobados. Los árbitros pueden aprobar un manuscrito en términos generales tal como está escrito, aprobarlo con modificaciones menores o mayores y definitivamente pueden rechazarlo. En todos los casos los autores deberán adelantar las correcciones hechas por los árbitros, las cuales deberán ser revisadas y comprobadas por el editor, quien previamente pedirá la relación de las mismas de acuerdo con el número de árbitros que hayan participado, así como algunas claves que ayuden a identificar las modificaciones. Teniendo en cuenta que mínimo deben ser dos árbitros los que participen en el proceso, en caso de recibir un rechazo, el editor deberá solicitar otro concepto o más si es necesario para definir la aprobación o rechazo final del manuscrito en cuestión (1).

Es pertinente resaltar que al momento de enviar los manuscritos a los árbitros, estos no llevan el nombre o nombres del autor o autores, filiación institucional, fuentes de financiación, agradecimientos o cualquier información adicional que pueda ayudar a la identificación del autor o los autores. Por otra parte, los autores tampoco conocen en ningún momento del proceso de sometimiento los nombres de los árbitros asignados. Cuando el editor recibe el concepto o dictamen del manuscrito por parte de los árbitros, el editor informa al autor los resultados de la evaluación sin revelar los nombres de los mismos. De todas maneras existe la posibilidad de que las partes intervinientes (autores, árbitros, lectores) hagan hipótesis o cábalas, sobre quien o quienes son los autores o los árbitros, en especial cuando esta responsabilidad recae exclusivamente en los miembros de un comité editorial numeroso. Por esta razón, es preferible un comité editorial de un reducido número de miembros y recurrir a evaluadores externos y ojalá internacionales. También es conveniente cuando la revista es multitemática como es el caso de la Rev.MVZ Córdoba que publica temas que estén relacionados con la medicina veterinaria, zootecnia, acuicultura, biología, biotecnología, ciencias básicas biomédicas y otros tópicos de interés de las ciencias agropecuarias. Esta misma característica per se obliga a la utilización de árbitros de diversas disciplinas, los cuales sería imposible reunirlos en un comité editorial. 
Los árbitros o pares deben reunir una serie de condiciones y características generales. Una de ellas, condición sine qua non, es que primero se es investigador y luego par o árbitro. Adicionalmente, los árbitros o evaluadores deben ser imparciales, deben evitar divulgar y utilizar material inédito de las investigaciones para uso propio o de otros grupos de investigación, deben mantener absoluta confidencialidad de la información inédita que les llega, deben estar activos publicando manuscritos, al menos durante los dos últimos años al momento de participar en un arbitraje y deben ostentar grados de M.Sc., o mejor aun de Ph.D. En sus informes o fichas de evaluación deben pronunciarse sobre las virtudes o méritos del trabajo, así como los defectos o debilidades y sugerir, en caso de ser posible, la forma de mejorar el manuscrito arbitrado. Tampoco es ético hacer ningún tipo de comentarios con otros investigadores sobre el manuscrito evaluado, bien sea a favor o en contra del mismo (2).

Indudablemente el papel que tienen los árbitros, pares o evaluadores en el proceso de sometimiento de manuscritos en una revista científica es insustituible, y ellos, definitivamente colaboran tanto con autores, editores y lectores, pues estos últimos son los usuarios de la información que se publica (1). Creemos que nadie duda la importancia de la revisión de los manuscritos por expertos y hoy día es una herramienta reconocida como un buen método para evaluar y quizás garantizar la calidad de la publicación de los resultados de las investigaciones. No obstante, también es posible que se cometan errores y no todo lo que se publique sea válido, existe por tanto, la posibilidad de estar o no de acuerdo con lo publicado. ¿Donde están los árbitros, pares o evaluadores? No es fácil conseguirlos, pues por su condición sine qua non de investigadores, siempre están ocupados, llenos de mucho trabajo y cumpliendo con múltiples compromisos, y a pesar de ello, logramos conseguir la colaboración de un gran número de ellos. Nuestros reconocimientos por su loable labor.

Marco González T. M.Sc. Salim Mattar V. Ph.D.

\section{REFERENCIAS}

1. Maria Palucci Marziale. El papel del investigador como productor y evaluador de artículos científicos. [En Linea]. Rev. Latino-Am. Enfermagem 2012; 20(2). URL Disponible en: http://www.scielo.br/ pdf/rlae/v20n2/es_01.pdf
2. J. Gérvas, M. Pérez Fernández. La revisión por pares en las revistas científicas. Atención Primaria 2001; 27(6):432-439. URL Disponible en: http://es.scribd.com/ doc/36312468/La-Revision-Por-Pares-enLas-Revistas-Cientificas 